\title{
CRISTINA PERI ROSSI EN TRIUNFO: GÉNERO Y SEXUALIDAD EN LA PRENSA DE LA TRANSICIÓN ESPAÑOLA ${ }^{1}$
}

\author{
Rafael M. Mérida Jiménez \\ Universitat de Lleida \\ rmmerida@filcef.udl.es
}

\begin{abstract}
RESUMEN: La obra periodística de Cristina Peri Rossi (Montevideo, 1941) ofrece un interesante contrapunto a su actividad literaria, dada su sorprendente variedad temática. Este artículo cataloga y analiza los artículos de la poeta y narradora en Triunfo, una de las revistas más importantes durante el tardofranquismo y la Transición en España, prestando atención preferente a aquellas cuestiones en torno al género y a la sexualidad que mejor pueden dialogar con la poesía que publicó durante la década de los 70 (por ejemplo, Diáspora, publicado en 1976) y con su pensamiento feminista.
\end{abstract}

PALABRAS CLAVE: Cristina Peri Rossi, artículos en prensa, Triunfo, Género, Sexualidad, Transición en España.

\section{CRISTINA PERI ROSSI IN TRIUNFO: GENDER AND SEXUALITY IN SPANISH TRANSITION PRESS}

ABSTRACT: Cristina Peri Rossi's press articles offer an interesting approach to consider her literary work, revealing a surprising variety of topics. This essay catalogues and analyzes her collaborations in Triunfo, one of the leading magazines in Spain during the last years of Franco's regime and the transition to democracy. These pages deal with the role of gender and sexuality in order to reconsider if there is any dialogue between the issues Peri Rossi (Montevideo, 1941) developed in mass media during the 70s and her poetry (for example, Diáspora, 1976), as well as with her feminist point of view.

KEYWORDS: Cristina Peri Rossi, press articles, Triunfo, Gender, Sexuality, Transition in Spain.

Recibido: 23/03/2015. Aceptado: 02/06/2015

1. Este trabajo se ha desarrollado en el marco del GRC Creación y pensamiento de las mujeres (2014 SGR 44) y del proyecto de investigación FEM2015-69863-P. 


\section{Contextos}

El sitio de internet de Cristina Peri Rossi (Montevideo, 1941) constituye la privilegiada puerta de entrada a uno de los universos literarios femeninos más sugerentes, por plurales, de las letras hispánicas de las últimas décadas ${ }^{2}$. Autora premiada y publicada muy tempranamente -su primer volumen de relatos, Viviendo, fue publicado en 1963-, resulta especialmente conocida en España, por su arraigo desde 1974, como consecuencia del exilio al que le forzó la dictadura militar uruguaya y que le obligó a trasladarse a Europa en 1972. La semblanza trazada por Elena Poniatowska (2005: 18) es resumen y retrato explícito de aquella transición:

Cristina Peri Rossi llegó a Barcelona el 20 de octubre de 1972. El Ministerio del Interior de Uruguay la privó de la nacionalidad uruguaya y no tuvo residencia legal en España ya que la dictadura franquista no había firmado la Convención de Ginebra acerca de los derechos humanos, entre ellos, el derecho de asilo. Forzada a dejar también Barcelona poco tiempo después, salió a París en 1974 a lo que ella llama "su segundo exilio". Sola, indocumentada y apartada, no creo que haya disfrutado París ya que cuando pudo regresar legalmente a España, lo hizo de inmediato y saltó a Barcelona en donde vive hasta la fecha.

La calidad de su dilatada trayectoria como creadora en muy diversos registros (de la poesía lírica, el relato breve o la novela, al ensayo, el artículo de prensa y la traducción) ha propiciado que sus obras hayan sido editadas en diversas lenguas y países; paralelamente, el interés de la crítica académica queda demostrado por el creciente volumen de trabajos durante las dos últimas décadas en torno a su obra poética y narrativa, en especial aquellos emplazados en los estudios sobre la mujer, el género y la sexualidad ${ }^{3}$. Es cierto que la difusión de la obra de Peri Rossi se consolidó en España sobre todo mediada la década de los 80, tras la publicación de La nave de los locos (1984) y Solitario de amor (1988); aunque cabría destacar que los relatos de La tarde del dinosaurio ya habían sido editados por Plaza y Janés a la altura de 1976 y que entre 1975 y 1979 fue en España en donde vieron la luz los versos de Descripción de un naufragio (1975), Diáspora (1976) y Lingüística General (1979a). En cualquier caso, resulta interesante constatar que en una panorámica tan rica como la

\section{2. http://cristinaperirossi.es/web/}

3. De entre la abundante bibliografía secundaria, solo destacaré ahora las monografías complementarias de Dejbord (1988) y Pertusa (2005). Elena Castro (2014: 12) justificaba la ausencia de nuestra autora en su monografía Poesía lesbiana queer con las siguientes palabras: "si parte de la labor que se lleva a cabo en este ensayo consiste en dar visibilidad a voces que hasta ahora han sido silenciadas o casi desconocidas, este no es el caso de Cristina Peri Rossi". 
que ofrecen Joaquín Marco y Jordi Gracia (2004: 35 y 185), a propósito de la recepción de las letras hispanoamericanas en España entre 1960 y 1981, Peri Rossi apenas sea citada en un par de ocasiones; sin duda, esta circunstancia se debe a que se concentre sobre todo en los autores vinculados a lo que suele denominarse "boom", órbita ajena a Peri Rossi, a pesar de sus obras narrativas de los años 60.

El objetivo de las presentes páginas no es abundar en la producción más conocida y valorada de esta autora, sino abordar una de sus facetas que, a mi entender, todavía no ha merecido la debida atención crítica, vinculada a sus colaboraciones en la prensa. Resulta en cierta medida sorprendente, si consideramos el aprecio explícito de Peri Rossi (2005: 29):

\begin{abstract}
A lo largo de más de 30 años de ejercicio del periodismo he abordado muchísimos temas, desde la filatelia al jazz, desde el cine al psicoanálisis, desde la técnica a la sexualidad, desde el fútbol a la genética, y mi principio sigue siendo el mismo: cualquiera de mis artículos podría figurar en mis Obras Completas. Es, por tanto, una tarea artística, y, también, un compromiso con cada momento histórico. Sigo creyendo que el escritor debe estar comprometido con la condición humana y por tanto, con los derechos de las personas, con la defensa de los valores de la Revolución Francesa y con la solidaridad que ha conservado a la especie a pesar de todas las catástrofes naturales y políticas.
\end{abstract}

Esta afirmación contundente aparece en el prólogo de la antología hermosamente titulada El pulso del mundo, que brinda una generosa selección de sus artículos periodísticos publicados entre 1978 y 2002 (Peri Rossi 2005). Su compiladora, Mercedes Rowinsky-Geurts, realizó una tarea de indudable atractivo, pues evitó la ordenación cronológica y nos invitó a adentrarnos mediante una organización en núcleos temáticos (viajes, ciudades, exilios, cuerpos, sexualidades, escrituras...) que acentúa una lectura menos deudora de la actualidad inmediata de la que partían las diversas piezas que de la sensibilidad, los gustos e intereses de la autora, presentes en unas piezas breves que no rehuían ni el presente inmediato ni la reflexión más perspicaz. Debe subrayarse que entre los rotativos en los que ha colaborado Peri Rossi destacan El País, Diario 16, El Mundo, ABC, El Periódico, La Vanguardia o El Norte de Castilla, entre otros, es decir, los mejores y más influyentes diarios españoles desde la Transición.

En este prólogo, igualmente, Peri Rossi traza su doble biografía periodística, tanto la vinculada a la lectora de prensa desde la infancia, en casa de su abuela materna, como durante su juventud, cuando inició sus colaboraciones en El Popular, diario del Partido Comunista de Uruguay. Este bagaje sería el que le permitiría empezar a colaborar en el semanario Marcha, tras ser galardonada en 1968 con el Pre- 
mio Arca de Narrativa por su libro de relatos Los museos abandonados, que concedía un jurado presidido por Ángel Rama, entonces director de las páginas literarias de esta influyente revista, no solo en Uruguay sino en toda Hispanoamérica: "Cuando por motivos políticos tuve que abandonar el país, como tantos otros uruguayos, las dos cosas que perdí con más dolor fueron: mi profesión docente y Marcha [...]. [N]o pude continuar colaborando con el semanario, porque mi nombre, mis libros y mis textos fueron prohibidos por la dictadura militar" (Peri Rossi 2005: 27).

Aquello que resulta ahora más interesante es que el azar propiciara que nuestra autora comenzara a colaborar en el semanario Triunfo, una de las cabeceras más relevantes en la España de las décadas de los 60 y 70, cuando, con la censura franquista todavía vigente -aunque menos férrea por la Ley de Prensa de 1966-, se convirtió en valedora de un régimen democrático. Dicho con otras palabras, Peri Rossi reinició su actividad periodística en la revista española que, salvadas todas las distancias, mejor podía equipararse a Marcha:

Los amigos nuevos, los recién hechos así, en el exilio, me presentaron la revista Triunfo. Me la presentaron como se presenta una seña de identidad, un emblema, lo mejor de nosotros mismos. [...] [R]econocí, en Triunfo, una sensibilidad común, unos ideales compartidos, una visión del mundo semejante. Podríamos llamarlo, reconociendo la importancia del lenguaje, el espíritu de una época. [...] Creo que Triunfo fue parte fundamental del espíritu de una época. [...] Fue una época irrepetible (no digo ni mejor ni peor) y quizás el último proyecto y obra de la modernidad en España. (Peri Rossi 1995: 279-280)

La importancia del semanario Triunfo resulta indiscutible para cualquier estudio de la prensa del tardofranquismo (Alted - Aubert 1995). Fundado por José Ángel Ezcurra en 1946, se convirtió a partir de su refundación en 1962 y hasta su cierre, en 1982, en un referente irrenunciable de los lectores opositores al régimen o claramente de izquierdas. En sus páginas colaboraron muchos de los periodistas y académicos más comprometidos e influyentes entonces (y después): de Eduardo Haro Tecglen a Manuel Vázquez Montalbán, pasando por Luis Carandell, Ignacio Ramonet, Víctor Márquez Reviriego, Juan Luis Abellán, Enrique Miret Magdalena, Manuel Vicent y Fernando Savater. O, lo que podría describirse como "toda una generación de escritores y periodistas que luego de la muerte del dictador construirían la transición y harían un periodismo creativo, muy inspirado" (Peri Rossi 2005: 27).

La nómina, que podría ser extensísima, revela una realidad incontestable: la abrumadora presencia de varones. Es un dato objetivo que Peri Rossi (2005: 2728) describe de la siguiente manera: 
Yo vivía en Barcelona y trabajaba en una pequeña editorial, pero en el año 1974 conseguí que Triunfo (donde tampoco escribían mujeres, porque la Revolución de las Mujeres todavía estaba en pañales) publicara un artículo mío sobre la Fundación Joan Miró. A partir de ese momento, fui colaboradora estable de la revista, y ella se convirtió, para mí, en el sucedáneo de Marcha. Enviaba mis artículos por correo, y jamás me rechazaron uno.

Se trata de una apreciación personal, pues durante la década de los 70 ya colaboró en la revista una autora tan indispensable como Montserrat Roig, por citar un caso emblemático para la literatura feminista catalana. Recuérdese que a la altura de julio de 1976 empezó a publicarse la revista Vindicación feminista, de Lidia Falcón y Carmen Alcalde, en la misma Ciudad Condal en cuya universidad se habían desarrollado dos meses antes unas históricas "Jornades Catalanes de la Dona" de hondo calado político (Nash 2007).

El pulso del mundo solo recoge tres de las piezas publicadas en la afamada cabecera española, todas ellas de $1978^{4}$. Sin embargo, merece rescatarse que se trata de un conjunto de colaboraciones que supera la cincuentena, volumen que refleja no solo las opiniones y los análisis de la autora, en absoluto inocuos, sino un diálogo con su tierra de acogida de muy variados matices: "Mis artículos de Triunfo abarcaban toda la realidad española, desde la apertura de los casinos de juego hasta el consumo de marihuana, desde el asesinato de Allende a los ensayos feministas de Virginia Woolf" (Peri Rossi 2005: 28). Esta disparidad sería la única que justificaría que la monografía de Paola Bellomi (2011), consagrada al estudio de las páginas literarias de Triunfo entre 1970 y 1978 -en cuyo título se concilian los conceptos "periodismo cultural" y "compromiso político" -, no mencione a nuestra autora. Entiendo que esta investigación se centra en aquellos trabajos directamente consagrados a la recepción de la narrativa, la poesía y el teatro, pero resulta paradójico, a mi gusto, que no cite en ningún momento la presencia de Peri Rossi en varias secciones de la revista, teniendo en cuenta que no podía considerársele una creadora novel ${ }^{5}$. No sería hasta 1979 que Rosa $\mathrm{M}^{\mathrm{a}}$ Pereda reseñó su poemario Lingüística general ${ }^{6}$.

4. Se trata de los artículos titulados "Estado de exilio" (4 de febrero de 1978), "Las drogas blandas" (26 de agosto de 1978) y "Guyana: el último rito" (2 de diciembre de 1978). Véase Peri Rossi (2005: 6569, 165-170 y 281-286).

5. En 1978, Cristina Peri Rossi publicó varios artículos vinculados a noticias literarias: "Eduardo Galeano y Claribel Alegría: Premio Casa de las Américas", no 790 (18 de marzo), "César Vallejo: demasiado humano", no 796 (29 de abril); "Copi: la imaginación a escena", nº 806 (8 de julio); "Virginia Woolf: tres guineas de feminismo", n 808 (22 de julio) o "Eduardo Galeano: el amor y la guerra", nº 830 (23 de diciembre). En notas posteriores ofrezco listados completos de sus colaboraciones, agrupadas cronológicamente.

6. No debe obviarse, en todo caso, que algunas colaboraciones periodísticas nacieran por puro interés material, como cuando en un volumen autobiográfico en donde rememora su amistad con Julio Cortázar, 


\section{Textos}

Los artículos que Cristina Peri Rossi publicó en el semanario madrileño resultan muy variados no solo por la temática, según ella misma afirma, sino por su extensión, la modalidad de prosa y el tono empleados. Ante esta diversidad, valoraré aquellas cuestiones que más nítidamente se emplazan en la encrucijada de los estudios del género y la sexualidad con el objetivo de reevaluar la importancia de estas piezas en su contexto socio-histórico, a partir de 1978. El año elegido deriva de una circunstancia nada aleatoria: tras una consulta de la revista, que queda confirmada a través de sus índices, no habría aparecido ningún artículo con anterioridad. Este dato contradice el recuerdo citado de la propia autora, en donde afirmaba que colaboraba en Triunfo desde 1974. En los índices de la revista no aparece ningún artículo suyo entre 1974 y 1977; en 1975 solo fue publicado uno en torno a la Fundación Miró de Barcelona, durante el mes de junio, con firma de Manuel Vázquez Montalbán (1975). De manera que no debiera aceptarse ese año: bien puede tratarse de una errata o de simple desmemoria. Un vaciado de la revista solo arroja colaboraciones suyas entre los años 1978 y 1982 (lo que coincidiría, de hecho, con el año en que se inicia El pulso del mundo). Algo no encaja en el recuento: Peri Rossi publicó un artículo en 1978 sobre la Fundación Joan Miró ${ }^{7}$, pero tampoco era su primer artículo en $\operatorname{Triunfo}^{8}$. Desde cualquier perspectiva, y por múltiples razones, 1974 estaba muy cerca y al tiempo muy lejos de 1978 para un medio de comunicación en España -igual que para la inmensa mayoría de españoles-, empezando por el hecho de que ya no existiera la censura legal previa.

En el año 1978, Peri Rossi publicó en Triunfo un total de 25 artículos y notas $^{9}$, mientras que en el año 1979, el número total de colaboraciones fueron

Peri Rossi (2014: 75) llega a admitir: "No te escribí poemas. En realidad, ahora que lo pienso, salvo alguna entrevista que te hice y publiqué en España, por motivos estrictamente económicos (las penurias del exilio), nunca escribí explícitamente sobre vos, mientras estabas vivo".

7. "Premio europeo a la Fundación Miró: un museo vivo", nº 789 (11 de marzo).

8. Con anterioridad habían visto la luz otros tres, como se indicará en la siguiente nota.

9. [1] "Muñecas", no 782 (21 de enero); [2] "Estado de exilio", no 784 (4 de febrero); [3] "Noticiari de Barcelona: en busca de una identidad nacional", $\mathrm{n}^{\circ} 787$ (25 de febrero); [4] "Premio europeo a la Fundación Miró: un museo vivo", no 789 (11 de marzo); [5] "Eduardo Galeano y Claribel Alegría: Premio Casa de las Américas", n 790 (18 de marzo), [6] "Santiago Álvarez: un cine militante", n 793 (8 de abril); [7] "Pornografía y sociedad", no 794 (15 de abril); [8] "César Vallejo: demasiado humano", nº 796 (29 de abril); [9] "Sex-Pol: la revolución sexual y política", no 796 (29 de abril); [10] "Así hablaba Lou Salomé”, no 800 (27 de mayo); [11] “A propósito de Voltaire”, no 801 (3 de junio); [12] "Ocaña: retrato de un impertinente", no 803 (17 de junio); [13] "Llorar por vos, Argentina", no 805 (1 de julio); [14] "Copi: la imaginación a escena", no 806 (8 de julio); [15] "Virginia Woolf: tres guineas de feminismo", n 808 (22 de julio); [16] "Mediterráneo, vertedero nostrum", no 810 (5 de agosto); [17] "Los viajes", no 812 (19 
$17^{10}$. Este bienio fue el más fructífero, ya que entre 1980 y 1982 el volumen es ostensiblemente menor: 10 artículos ${ }^{11}$. La mayoría tratan sobre cuestiones en donde la sexualidad o el género estuvieron ausentes: tras una simple lectura, resulta evidente que Peri Rossi no fue reclutada para abordar estas temáticas o que ella misma -si aceptamos sus palabras citadas a propósito de la libertad con la que trabajó- prefirió no centrarse en un único ámbito, pues tantos o más artículos abordaron cuestiones políticas, culturales o sociales muy diversas y alejadas. Las contribuciones de Peri Rossi, en todo caso, podían brindar, claro está, una visión femenina de asuntos y problemas candentes que equilibraba la nómina masculina de colaboradores a la que ya he aludido. Subyace más una preocupación general por las desigualdades de cualquier índole, propia del pensamiento izquierdista que guiaba la revista, que específicamente feminista.

Esta afirmación no debe confundirnos, pues nuestra autora muestra nítidamente su ideología en la extensa entrada con la que introduce su entrevista a Lidia Falcón, en ocasión del nacimiento del Partido Feminista -y que podría constituir por sí misma una nota independiente-, de la que reproduzco la sección final:

de agosto); [18] "Las drogas blandas", nº 813 (26 de agosto); [19] "Hagan juego, señores", no 814 (2 de septiembre); [20] “¿Me permite usted este baile?”, no 820 (14 de octubre); [21] "Nosotros los delincuentes", no 821 (21 de octubre); [22] "Lengua y política", no 824 (11 de noviembre); [23] "Guyana: el último rito", no 827 (2 de diciembre); [24] "Ha llegado Hauden Caufield", n 829 (16 de diciembre), y [25] "Eduardo Galeano: el amor y la guerra", $\mathrm{n}^{\circ} 830$ (23 de diciembre).

10. [1/26] "Los filicidios", no 834 (20 de enero); [2/27] "Adiós a los sistemas", no 836 (3 de febrero); [3/28] "Holocausto", $n^{\circ} 837$ (10 de febrero); [4/29] "Lectura de la imagen política", no 840 (3 de marzo); [5/30] "El auge de la novela negra: Spade y Marlowe en la calle Conde del Asalto", n ${ }^{\circ} 842$ (17 de marzo); [6/31] "Sonata en Bergman conservador", no 843 (24 de marzo); [7/32] "Demanda", no 852 (26 de mayo); [8/33] "El naranjito", no 854 (9 de junio); [9/34] "Las mujeres ya tienen partido", no 855 (16 de junio); [10/35] "Hacia el desorden amoroso", $n^{\circ} 857$ (30 de junio); [11/36] "Uruguay: los cumpleaños de la dictadura”, nº 858 (7 de julio); [12/37] "La rebelión de los automóviles", nº 860 (21 de julio); [13/38] "Hombres ricos, hombres pobres", $n^{\circ} 862$ (4 de agosto); [14/39] "A cada cual su propio ovni”, $n^{\circ} 866$ (1 de septiembre); [15/40] "Argentina: maneras legales de morir", $\mathrm{n}^{\circ} 869$ (22 de septiembre); [16/41] "Una ciencia llamada economía", no 873 (20 de octubre), y [17/42] "Heliodoros", no 878 (24 de noviembre).

11. En 1980, Peri Rossi publicó las siguientes colaboraciones: [1/43] "Del apocalipsis que no sobrevendrá”, no 885 (12 de enero); [2/44] “¿Fueron felices los cuarenta?”, nº 888 (2 de febrero); [3/45] "Grandes relatos", $\mathrm{n}^{\circ} 890$ (16 de febrero); [4/46] "Ding-dong", no 905 (31 de mayo); [5/47] "¡Vivan los genes!", nº 897 (5 de abril); [6/48] "Divorciémonos, amor mío", nº 911 (12 de julio). Entre 1981 y 1982 aparecerían sus últimos artículos, en la nueva época de la revista (que pasó de semanal a mensual), con nueva numeración: [7/49] "La bomba", nº 5 (1 de marzo de 1981); [8/50] "Menú atípico", n 9-10 (1 de julio de 1981); [9/51] "Retrato del videófilo impenitente", $\mathrm{n}^{\circ} 11$ (1 de septiembre de 1981), y [10/52] "Los inventores arrepentidos", n 18 (1 de abril de 1982). 
Esta alienación no es muy diferente de la real; mujeres recluidas en el 'ghetto' del hogar, o productos de consumo para las revistas pornográficas, mujeres sometidas o discriminadas, mujeres frustradas en sus aspiraciones individuales por una sociedad y una clase que oculta las continuas sevicias y humillaciones a que las somete, no sin sublimar el rol, faltaría más: frente a la explotación económica y sexual de las mujeres, entona el canto de la sacralización de la maternidad, el de custodia de valores, el de reposo-del-guerrero y buena enfermera. A las esclavas hay que convencerlas de que son imprescindibles para que el edificio de la civilización no se destruya. Pero la rebelión se ha iniciado. Las mujeres, unas mujeres, mejor dicho, acaban de fundar el Partido Feminista (Peri Rossi 1979b: 57).

Hay, por supuesto, un interés indudable en presentar centralidades y periferias que deben rescatarse a propósito de la situación de la mujer en la España de la Transición. A veces el tema se introduce como núcleo central, como cuando aborda una futura ley de divorcio (Peri Rossi 1980). En ocasiones, un artículo sirve como excusa para dejar caer aquí o allá comentarios acerados: por ejemplo, en el dedicado a la prensa pornográfica (Peri Rossi 1978c), y a propósito de las muñecas hinchables que los espectadores españoles ya conocerían a través de la cinta $T a$ maño natural (1973) de Luis García Berlanga, afirma: "Un ser privado de respuesta, del don de enjuiciar y decidir, de la capacidad para actuar por sus propios medios, puede llegar a constituirse, en una sociedad maltrecha como la nuestra, en el único dispensador de placer sin conflictos" (Peri Rossi 1978a: 37). También se introduce ese pensamiento al calor de novedades editoriales tan diferentes como unos libros de fotografía (Peri Rossi 1978b), Tres guineas de Virginia Woolf (Peri Rossi 1978f) y El nuevo desorden amoroso de Pascal Bruckner y Alain Finkielkraut (Peri Rossi 1979c), o el estreno de Más allá del bien y del mal (1977), la polémica película de Liliana Cavani. Su análisis de la figura de Lou Andreas Salomé resulta especialmente destacable:

La falta de dependencia de Salomé en cuanto a su relación con los hombres, su asunción de la igualdad sin rivalidad y sin exclusión del macho me parecen uno de los planteos modernos más lúcidos y coherentes sobre la feminitud, esa categoría que no puede confundirse con la femineidad y a veces tampoco con el feminismo, si éste se limita a repetir los modelos de comportamiento y de conducta de los hombres, en la vida pública y en la privada. Haber conseguido crear una mujer absolutamente diferente, cuyos actos no están regidos por otro patrón más que el de la autenticidad y la libertad interior es el núcleo del film y sobre la integridad de esta criatura reposa su coherencia (Peri Rossi 1978d: 67).

Son muy pocos los artículos de nuestra autora que se adentren en la realidad de las minorías sexuales, hecho sorprendente porque puede destacarse que en 
Triunfo, entre 1977 y 1979, los artículos sobre esta temática no dejaron de estar presentes, ya que se hacían eco combativo de las primeras reivindicaciones públicas en las calles de las grandes ciudades españolas: así lo corroborarían las piezas firmadas por Juan Goytisolo (1977), Julia Luzán (1977) y Eduardo Haro Ibars (1978), entre otros. Puede sorprender que en estos artículos no se ofrezcan alusiones explícitas al lesbianismo, cuya invisibilidad resulta clamorosa, habida cuenta de que en los poemarios de esta década, desde Evohé (1971) hasta Lingüística general (1979), no lo silenció (Fariña Busto 2000), según proclama uno de los poemas más citados de Diáspora:
A los poetas que alabaron su desnudez
les diré:
mucho mejor que ella quitándose el vestido
es ella desfilando por las calles de Nueva York
-Park Avenue-
con un cartel que dice:
"Je suis lesbianne. I am beatiful" (Peri Rossi 1976: 63).

En cambio Peri Rossi arremete contra determinadas actitudes de los varones gais: "Los 'gay', las locas (término detestable pero autoadjudicado por los travestis), los adictos a determinadas drogas comienzan por ser marginados hasta convertirse en grupos sociales perfectamente identificables por sus señas de identidad exterior" (Peri Rossi 1978g: 53). La asociación resulta extraña desde nuestra perspectiva, pero imagino que sincera por entonces, pues se reitera; cuando describe la fauna que puebla las Ramblas barcelonesas, a manera de introducción a la personalidad del protagonista de la película de Ventura Pons titulada Ocaña, retrato intermitente (1978), apunta:

En ese largo paseo que va a dar al mar, allí donde la estatua de Colón nos advierte con un gesto de la mano, de día se mezclan los puestos de libros con las flores, las jaulas con canarios y las ediciones de "La Stampa" y "Le Monde". Al atardecer, en cambio, el camino de las Ramblas se puebla con una multitud heterogénea: cuando los buenos ciudadanos terminan su trabajo dejando su cuota diaria de plusvalía, los marginados, los seres nocturnos, los rebeldes con causa, los homosexuales, los tullidos, los travestis, los poetas sin suerte y sin fama, los dibujantes de a trescientas pesetas su rostro o el de su actriz favorita, las prostitutas, los parados, los locos inofensivos, los exhibicionistas, los emigrantes de dentro y de fuera, los delincuentes menores y los mendigos comienzan a transitar y a vivir la noche. Ocaña ha sido uno de los animadores más frecuentes y provocativos de las Ramblas [...] (Peri Rossi 1978e: 56). 
Más allá de la variedad temática y de los tonos manejados, resulta evidente que el tapiz (in)voluntario que Cristina Peri Rossi fue tejiendo en sus colaboraciones en Triunfo no pasaría algunos cedazos de la corrección política y sexual a estas alturas del siglo XXI. Tampoco dialogan con su obra poética coetánea y posterior, en la que el deseo lésbico ha sido una presencia explícita. No creo que a estas colaboraciones se las pueda valorar a la manera de cuanto resume Elena Poniatowska (2005: 17) a propósito de sus trabajos posteriores en la prensa: “[s]us artículos son notables por su investigación y su reflexión y brindan al lector un consejo, una enseñanza, un aprendizaje, una advertencia". Sin embargo, sí que resultan de indudable atractivo para profundizar en la sociedad española de la Transición y merecerían una edición tan atenta como bien anotada.

\section{Bibliografía}

ALTED, A. y AUBERT, P. (Eds.) (1995). “Triunfo” en su época. Jornadas organizadas en la Casa de Velázquez los días 26 y 27 de octubre de 1992. Madrid: École des Hautes Études Hispaniques - Ediciones Pléyades.

BELLOMI, P. (2011). Periodismo cultural y compromiso político. Las páginas literarias de "Triunfo" (1970-1978). Cáceres: Universidad de Extremadura.

CASTRO, E. (2014). Poesía lesbiana queer. Cuerpos y sujetos inadecuados. Barcelona: Icaria.

DEJBORD, P. T. (1988). Cristina Peri Rossi, escritora del exilio. Buenos Aires: Galerna.

FARIÑA BUSTO, M. J. (2000). “Condición de mujer: las políticas del género en la obra poética de Cristina Peri Rossi” en Escribir en femenino: poéticas y políticas. (Ed. B. Suárez Briones et al.). Barcelona: Icaria, 235-248.

GOYTISOLO, J. (1977). "[Izquierda y homosexualidad.] Demos la vuelta de una vez, como un calcetín, a su miserable discurso", Triunfo 754 (9 de julio): 40-41.

HARO IBARS, E. (1978). "Peligrosos sociales. Lucha de todos", Triunfo 805 (1 de julio): 52.

LUZÁN, J. (1977). "La homosexualidad quiere salir del 'ghetto", Triunfo 759 (13 de agosto): 35-37.

MARCO, J. y GRACIA, J. (Eds.) (2004). La llegada de los bárbaros. La recepción de la literatura hispanoamericana en España, 1960-1981. Barcelona: Edhasa.

NASH, M. (2007). Dones en transició. De la resistència política a la legitimitat feminista: les dones en la Barcelona de la Transició, Barcelona: Ajuntament.

PEREDA, R. M. (1979). "Cristina Peri Rossi: las investigaciones paralelas", Triunfo 877 (17 de noviembre): 57-58.

PERI ROSSI, C. (1971). Evohé. Montevideo: Girón. 
PERI ROSSI, C. (1975). Descripción de un naufragio. Barcelona: Lumen. PERI ROSSI, C. (1976). Diáspora. Barcelona: Lumen.

PERI ROSSI, C. (1976). La tarde del dinosaurio. Barcelona: Plaza y Janés. PERI ROSSI, C. (1978a). "Muñecas", Triunfo 782 (21 de enero): 34-35.

PERI ROSSI, C. (1978b). "Mujeres bajo la lente", Triunfo 785 (11 de febrero): 36-37.

PERI ROSSI, C. (1978c). "Pornografía y sociedad", Triunfo 794 (15 de abril): 42-43.

PERI ROSSI, C. (1978d). “Así hablaba Lou Salomé”, Triunfo 800 (27 de mayo): 66-67.

PERI ROSSI, C. (1978e). "Ocaña: retrato de un impertinente", Triunfo 803 (17 de junio): 56-57.

PERI ROSSI, C. (1978f). "Virginia Woolf: tres guineas de feminismo", Triunfo 808 (22 de julio): 44-45.

PERI ROSSI, C. (1978g). “Me permite usted este baile?”, Triunfo 820 (14 de octubre): 52-53.

PERI ROSSI, C. (1979a). Lingüística General. Valencia: Prometeo.

PERI ROSSI, C. (1979b). "Las mujeres ya tienen partido", Triunfo 855 (16 de junio): 57-59.

PERI ROSSI, C. (1979c). "Hacia el desorden amoroso", Triunfo 857 (30 de junio): 42-43.

PERI ROSSI, C. (1980). "Divorciémonos, amor mío”, Triunfo 911 (12 de julio): 12. PERI ROSSI, C. (1984). La nave de los locos. Barcelona: Seix Barral.

PERI ROSSI, C. (1988). Solitario de amor. Barcelona: Grijalbo.

PERI ROSSI, C. (1995). "Una nave llamada Triunfo", en "Triunfo" en su época. (Ed. A. Alted y P. Aubert). Madrid: École des Hautes Études Hispaniques Ediciones Pléyades: 279-280.

PERI ROSSI, C. (2005). El pulso del mundo. Artículos periodísticos: 1978-2002. (Ed. M. Rowinsky-Geurts). México: Universidad Autónoma de la Ciudad de México.

PERI ROSSI, C. (2014). Julio Cortázar y Cris. Palencia: Cálamo.

PERTUSA, I. (2005). La salida del armario. Lecturas desde la otra acera: Esther Tusquets, Carme Riera, Sylvia Molloy, Cristina Peri Rossi. Gijón: Libros del Pexe. PONIATOWSKA AMOR, E. (2005). "Presentación" en El pulso del mundo. Artículos periodísticos: 1978-2002, de Cristina Peri Rossi. México: Universidad Autónoma de la Ciudad de México: 13-22.

VÁZQUEZ MONTALBÁN, M. (1975). "La Fundación Miró: un mausoleo o una herramienta”, Triunfo 664 (21 de junio): 64. 